\title{
Transmisión del trauma en hijos de la Dictadura
}

\author{
Natalia Hidalgo Leiva'
}

"Transmitir es dejar huella. Es inscribirnos en la corriente de la vida sin saberlo. Sin pretenderlo. Para que otros la vuelvan a transmitir de otra mane-

ra, a su manera.

Transmitir en psicoanálisis es analizar. Con las huellas de aquellos que nos analizaron. Sin saberlo, sin pretenderlo. Para que otros vuelvan a analizar, a su manera, con nuestras huellas". ${ }^{2}$

La cuestión del trauma llamado real desde el psicoanálisis de orientación lacaniana ha sido menos estudiado que otros aspectos de la dinámica psíquica. Soler (1998) atribuye esto a la incomodidad del acontecimiento externo en relación a la implicación subjetiva. Sin embargo, la noción de trauma constituye para Freud un tema nodal de su investigación en el descubrimiento del inconsciente y el fantasma. Los autores que, basados en el pensamiento de Lacan, se han referido a un trauma de naturaleza diversa a la del fantasma, otorgan, sin embargo, claves que permiten situar ejes de anudamiento a mi parecer de gran relevancia, por cuanto sitúan la realidad, en tanto realidad psíquica, en su vinculación con el registro de lo real como formulación central del trabajo de Lacan.

A partir de ello es posible desprender desde la perspectiva señalada, una lectura sobre la transmisión de lo traumático, vehiculizada por el significante. Este artículo se propone presentar algunos ejes sobre los cuales situar la comprensión de las nociones de trauma y de transmisión, aplicado a la violencia política en Chile y, más específicamente, sobre la base de una clínica en particular: el abordaje desde el Programa PRAIS que ha diseñado el Estado chileno con el encargo de reparar secuelas de lo traumático y cómo el encargo derivado de ello puede ser pensado y aplicado en la población

1 Chilena. Psicóloga de la Universidad de Chile, Magíster en Psicología Clínica de Adultos, mención Psicoanálisis. Profesional del equipo del Programa de Reparación y Atención Integral en Salud (PRAIS) del Servicio de Salud Metropolitano Oriente de la Región Metropolitana, Hospital Salvador de Santiago. Psicóloga en CAPS Academia de Humanismo Cristiano. Este artículo es parte de una investigación realizada en la tesis para optar al grado de Magíster en Psicología Clínica de Adultos, mención Psicoanálisis, impartido por la Universidad de Chile, 2015. E-mail: nataliajh|@gmail.com

2 Weschler, 2013: 9. 
de los hijos de los afectados directos por la represión política durante la dictadura en nuestro país.

\section{Trauma real, trauma originario}

"El traumatismo es uno de los nombres que
recibe la efracción de la desgracia cuando
proviene desde afuera, por sorpresa, sin que
se la pueda imputar al sujeto".

Trauma es una noción que, como otras, cuenta con tantas comprensiones como vertientes de pensamiento. Desde la medicina a la psiquiatría clásica y desde los distintos psicoanálisis, requiere de cierta precisión al momento de recurrir a ella en tanto categoría de análisis. Eric Laurent (2002) se refiere a la 'era del trauma' para aludir a una forma de abordaje de las desgracias humanas que en la actualidad se generaliza: demasiadas formas y dimensiones del dolor humano son entendidas como trauma. Soler (1998), desde esta misma perspectiva, señala que es efectivo que los sujetos pueden ser hoy más vulnerables, más traumatizables, toda vez que la protección respecto de lo real está dada por los discursos que el Otro despliega, la consistencia y coherencia de estos. Hoy en día los discursos, dice la autora, se encuentran agujereados. La noción de discurso-pantalla acude a definir este soporte significante.

La imprecisión se encuentra atravesada, según Soler (1998), por el hecho de que los psicoanalistas 'clásicos' podrían sentirse más cómodos dentro de conceptualizaciones como fantasma y síntoma, que conllevan una implicación subjetiva de entrada. En el trauma real o contingente, como lo definiremos, existe en principio una falta de implicación del sujeto, lo que resulta complejo al psicoanálisis en cuanto método, dado que es ésta la puerta de entrada. Entonces, un trauma de esta naturaleza pone en juego los límites y bordes de la técnica psicoanalítica. Sin embargo, es también notorio en la clínica la forma en que un trauma producido por un evento externo, fáctico, remueve los fantasmas y síntomas propios de los sujetos. Se trata de eventos excesivos que parecen condensar, necesariamente, elementos asociados a lo extremo proveniente del 'exterior' (real) con aquellos que responden a la dinámica particular de cada subjetividad. La primera distinción es entonces entre el evento y la significación personal, de manera que no es posible señalar por sí solo un evento cualquiera como trauma; tal calidad deviene en la relación con lo singular del sujeto.

Soler, 1998: 16. 
Desde la perspectiva lacaniana varios autores han distinguido el trauma originario, también nombrado como estructurante o constituyente, del trauma real o contingente. Uno para referirse al paso por el Complejo de Edipo en tanto renuncia al objeto originario, cuyo paradigma se encuentra en lo materno en calidad de función de Otro primario en su forma absoluta y total, con su indiferenciación original, la irrupción necesaria y estructurante de la función paterna que conlleva un corte exigente de procesar para la psiquis, y que resulta determinante en su estructuración subjetiva, a la manera de un punto crítico.

El trauma real, en cambio, se emparenta con la violencia secundaria como la entiende Aulagnier (1975): violencia innecesaria y amenazante. Que no estructura sino desarma lo ya establecido, desorganizando al sujeto de manera más o menos devastadora.

Considerar lo anterior implica una consecuencia clínica que adquiere la mayor relevancia: el trabajo analítico no estaría centrado solamente en contenidos inconscientes ligados al fantasma edípico, sino muchas veces y de manera concreta en la forma de una investigación sobre la realidad de la historia familiar que permita restituir la continuidad conforme a su interrupción por un trauma real. Entre otras especificidades técnicas asociados a los vacíos en la representación y dificultades en la simbolización de experiencias extremas.

\section{Transmisión de lo traumático}

Soler (1998) ha señalado que es por la vía del significante que un goce puede ser transmitido, a través de los discursos, portadores de ciertos énfasis, silencios y vacíos de representación, que traspasan las cadenas transgeneracionales e intergeneracionales. Las huellas nos constituyen y puede ser necesario hacer un trabajo al respecto cuando ellas generan padecimiento.

Entonces los pacientes a través de sus síntomas, malestar psíquico y la forma de su discurso, testimonian no sólo sobre su presente, sino que también acerca de una cadena de generaciones pasadas, en la forma de un discurso que se encuentra entre sombras y da cuenta de una "constelación familiar" que precede el nacimiento (Lacan, 1953, en Weschler, 2005: 6). Sobre ella, el sujeto construye un fantasma que configura la forma en que aparece la propia responsabilidad subjetiva sobre aquello que le es transmitido. En el análisis circula una cierta verdad acerca de ambos aspectos de la transmisión; verdad que ha de ser encontrada, producida y construida, y en el caso de generar un goce mórbido, develarlo. La premisa freudiana propone adquirir lo heredado de los padres, con el fin de poseerlo, hacerlo propio (Freud, 1923).

La transmisión de lo traumático adquiere ciertas particularidades específicas asociadas a la dificultad de los sujetos para hablar de ellas, hacer circular 
un discurso en torno suyo. Al ser imposible no transmitir contenidos de esta relevancia para la historia personal, este traspaso opera de todas formas a la manera de lo no dicho, de lo silenciado, generando una fantasmática particular que puede ser considerada como resultado de un quiebre o constituye uno en sí misma. Nos referiremos a ello en relación a lo transgeneracional.

"Las formas de transmisión que conducen a una mayor simbolización y complejización, son las ligadas a lo erótico y libidinal. En tanto que, cuando este trabajo psíquico se realiza bajo formas asociadas a lo tanático, la posibilidad de simbolizar se encuentra dañada en sus fundamentos. Esto indefectiblemente produce un quiebre en la transmisión" (Werba, 2002).

Entonces, desde la orientación lacaniana en psicoanálisis, comprendemos que la transmisión, vehiculizada por la palabra, respecto de los eventos avasallantes catastróficos adquiere cierta particularidad. La dificultad de representar experiencias extremas configura discursos cargados de ciertos énfasis y ciertos vacíos particulares. Bajo el aspecto de algo aberrante, extraño, excesivo o bloqueado, el material psíquico suele manifestarse con unas características cuya forma o contenido resulta diverso a todo lo demás, circulando en ocasiones al descubierto, excesivo y aberrante, como una herida abierta y, en ocasiones, camuflado entre otros contenidos, mostrando aspectos raros 0 extravagantes de mayor sutileza.

\section{Otros abordajes psicoanalíticos}

El abordaje de la transmisión transgeneracional se encuentra asociado a algunos conceptos y autores trabajados en relación a diversos traumas de origen "real". Abraham y Torok (1987) estudian la transmisión transgeneracional desde una filiación cercana a las formulaciones de Ferenczi y Melanie Klein. Introducen las nociones de fantasma y de cripta, para señalar con la primera a un elemento o materia parental inconsciente que se transmite sin ser introyectado, vale decir, sin mediar una elaboración psíquica. Quien porta un fantasma de la generación anterior, lo incluye sin introyectarlo ni saber de él; el contenido no constituye un producto del sujeto mismo.

La cripta es una noción que representa el entierro u ocultamiento de un material que resulta indecible para quien lo ha vivido. Una vivencia que produce un exceso imposible, es llevada a una bóveda psíquica, encapsulándose: "Abraham y Torok, afirman que la única realidad con status metapsicológico es la realidad denegada, escamoteada; es decir, el secreto. Para estos autores, la cripta que guarda el secreto tiene un lugar bien definido en la tópica. Este no es 'ni el inconsciente dinámico, ni el Yo de la introyección. Se trataría de un enclave entre los dos, una forma de inconsciente artificial, alojado en el 
seno mismo del Yo. Su existencia tiene como finalidad obturar los polos semipermeables del inconsciente dinámico. Nada debe filtrarse al exterior'. Llaman represión conservadora a la represión propia de la cripta para distinguirla de la represión constitutiva propia del inconsciente dinámico. La diferencia esencial entre ambas consiste en que en la histeria el deseo prohibido encuentra su camino a través de la realización simbólica, mientras que, en el cristóforo, el deseo ya ha sido realizado sin retorno. Este hecho permanece en el sujeto como un bloque de realidad perceptible en las desmentidas y denegaciones" (Abraham y Torok, 1987, en Werba, 2002).

Para la generación siguiente, quienes toman este secreto desprovisto de un trabajo de elaboración, queda el encargo de hacer el procesamiento psíquico de algo que no les pertenece. En este sentido se habla de identificaciones alienantes, que pueden ser a un antepasado muerto e idealizado, o a un evento que para la primera generación resulta humillante y/o vergonzoso. De estos postulados destaco la comprensión de lo que ellos nombran como "bloque de realidad" que se percibe a través de desmentidos y denegaciones. Operaciones que, desde la orientación lacaniana, se vinculan a lo perverso, como proceso y estructura.

Resulta del mayor interés para la clínica actual en PRAIS el hecho de que no sea el contenido lo relevante, dado que ya hemos intentado distinguir el evento de la significación psíquica, y que en esta institución se atiende a personas que han vivido experiencias diversas de represión política, además de pertenecer a distintas generaciones respecto a la vivencia. No sólo se trata de duelos por personas, cuando Abraham y Torok (1987) dedican una parte de su trabajo a los efectos de la identificación con un antepasado en la forma de aparición de muertos-vivos. Se trata de pérdidas simbólicas o excesos de violencia que se encuentran vinculados a la generación de síntomas y situaciones diversas. Tisseron, autor que sigue la misma línea de investigación, refiere que "lo innombrable puede adquirir la forma de fobias, compulsiones obsesivas, problemas en el aprendizaje, etc., que no están sólo ligadas al conflicto entre deseo y prohibición, sino también al conflicto entre el deseo de saber y comprender y las dificultades que el contexto impone a dicho conocimiento" (1995, en Werba, 2002: 298).

Desde una filiación similar, la noción de Gampel de transmisión radiactiva da cuenta de una manera de traspaso a los nietos de sobrevivientes, entendida como la penetración de contenidos traumáticos de una generación anterior, no metabolizados, que resultan dañinos al dificultar o impedir la formación de símbolos (2005: 64-65). Se trata de contenidos concretos que resultan intrusivos y desprovistos de sentido. Al estar por fuera de la representación, se expresan como actos que conmemoran algo "inquietante y extraño" de lo cual no puede hablarse: "Mis conceptos de 'identificación radiactiva' y de 'transmisión radiactiva' nos obligan a tomar conciencia del hecho de que no 
estamos protegidos contra los efectos de sucesos que se desarrollaron a una gran distancia geográfica y temporal. Y estos efectos no pasan por líneas identificatorias conocidas. Podemos ser 'receptores' pasivos. Podemos ser de manera completamente aleatoria, 'transmisores'".

La identificación radiactiva es trabajada en relación a los hijos de sobrevivientes de la Shoa, o bien hijos que son ellos mismos sobrevivientes. Mientras que la transmisión radiactiva es una noción que daría cuenta del proceso de traspaso a la generación venidera, vale decir, los nietos de los afectados directamente, en la investigación de Gampel (2005: 66). Lo complejo es que estas identificaciones no están disponibles, están fuera de los discursos de los cuales la familia es capaz de dar cuenta. Son inconscientes: "Dado que esas identificaciones radiactivas pertenecen al inconsciente, no pueden ser sometidas a la rememoración, sino solamente 'actuadas', es decir, traducidas en palabras o actos". Se trata de contenidos que no pudieron ser dichos, y que nos toca de alguna manera 'mostrar' antes que 'nombrar', a través de la observación de fenómenos clínicos que muchas veces se encuentran fuera del ámbito de la palabra.

\section{Los hijos de la Dictadura chilena}

"Es la generación que carga con la cicatriz mas no la herida, quien sostiene en su memoria el recuerdo, mas no la experiencia directa. Es la generación que se exige la obligación auto impuesta de esta herencia... describir la vivencia de sus padres; darle significado... e incluir ésta en la historia". ${ }^{4}$

Gampel trabaja con pacientes que o bien fueron niños que sobreviven a la Shoa, o bien son los hijos de estos sobrevivientes (2005: 81). Ambas situaciones se encuentran cruzadas por las pérdidas: de personas, del hogar, de la identidad familiar, de la historia biográfica, respecto de lo cual advierte que existiría una "imposibilidad de que los sobrevivientes que habían sido niños durante la Shoa pudieran elaborar su duelo. Entonces me planteé el problema del duelo en suspenso y de la psique habitada por muertos-vivos, un elemento que no les permitía a los sobrevivientes acoger y transformar las angustias existenciales proyectadas por sus hijos", limitando la capacidad parental de traducir y elaborar las experiencias de manera de permitir la transmisión de las mismas a sus hijos. Queda entonces cortada o resquebrajada esta transmisión.

4 Paul Celan, citado en Salvador, 2014. 
En los pacientes hijos que consultan en PRAIS, se observa cómo las experiencias que vivieron siendo niños forman parte de las dinámicas de funcionamiento de sus familias y de su propia constitución subjetiva temprana, por cuanto estos eventos sociales son tramitados en forma singular por quienes ejercían los roles parentales, cuyo anudamiento simbólico se encuentra en las funciones materna y paterna en tanto agentes de la transmisión significante. Las defensas desplegadas en calidad de pantallas protectoras, como también los espacios que quedaron fuera de ellas, vacíos de subjetivación, inciden directamente en la forma en que se impone lo real de los hechos y sus significaciones para la subjetividad en su presentación actual.

Son personas que habiendo vivido la dificultad de sus padres de hacer circular discursos que refieren a las experiencias de represión política, también fueron partícipes de los eventos en primera persona, siendo entonces niños. Esto otorga una doble complejidad al trabajo, pues existe una combinación de recuerdos propios, mito familiar, recuerdos encubridores y retazos de discurso parental, y en todo caso: "Los autores están de acuerdo sobre el hecho de que el genocidio y la persecución destruyen la capacidad y la función parental, y que los niños toman a cargo los conflictos psíquicos que pertenecen a la realidad vivida por los padres" (Ulriksen, 1998: 122).

Nótese que esta autora habla directamente de destrucción de la función parental. Y es que, de modo muy general, las investigaciones que se han realizado respecto de hijos de sobrevivientes del Holocausto y de las dictaduras del Cono Sur, coinciden en concluir que los efectos traumáticos en los padres afectan de manera negativa las competencias parentales, lo que incide en el desarrollo psíquico de los hijos. De igual manera, las familias desarrollan ciertos patrones vinculares que propician lo que se ha llamado transmisión del trauma, o transgeneracionalidad del daño.

Las manifestaciones clínicas que estos traumas transmitidos pueden adquirir han sido descritas: "El trauma transgeneracional y la transmisión de la victimización, ha sido explorada principalmente por sobrevivientes de la Shoah, abarcando los siguientes temas: furia, rabia y culpa, venganza, religión, identificación con el agresor, vergüenza, miedo, lástima, elaboración del duelo, estigmatización de víctima/sobreviviente, idealización del héroe, envidia, voyerismo, obediencia a la autoridad, identificación proyectiva, apego, angustia de separación, dogmas de guerra, lealtad, fidelidad, clandestinidad, pobreza, riqueza y un sinfín de estos temas que han sido abordados y otros más, que seguirán emergiendo" (Kurian-Fastlicht, 2012). Muchas de estas expresiones pueden ser reconocidas también en los hijos de la dictadura chilena.

Si clínicamente se observa en los hijos elementos de la historia que pueden ser considerados transmitidos, vale decir, tomados de la generación anterior, 
como se ha dicho, estos se presentan en conjunto con la construcción propia de los hechos a través de sus recuerdos, que encubridores o fragmentados, adquieren tanta relevancia como intensidad en cuanto a su significación psíquica. A partir de estas dos formas de presentación del material, encontramos una discusión acerca de lo que se ha considerado primera y segunda generación.

Elena Gómez (2012: 61), tras el abordaje del caso de Blanca, una mujer con características similares a los pacientes que nos ocupan por cuanto es hija y creció en dictadura, señala: "En ILAS hemos discutido y planteado que en el caso de los hijos como Blanca se produciría un tipo de experiencia traumática que al ser experimentada por el sistema parental, afecta a los hijos. Con estos últimos no es posible hablar estrictamente de una segunda generación, ya que ellos mismos han experimentado directamente una experiencia traumática, habitualmente en torno a la pérdida y a la separación, pero, al mismo tiempo, son hijos de padres que vivieron experiencias de persecución y el impacto de estos hechos está presente en sus vidas".

Por lo tanto, una de las distinciones que habría que realizar es sobre la generación de la que forman parte los hijos de los que trata este estudio. Debido a que se discuten y observan diferencias que, como señala uno de los trabajos de CINTRAS (2012: 71-73), se han establecido entre los estudios del Cono Sur y los trabajos realizados en Europa, Canadá, Estados Unidos e Israel respecto de los sobrevivientes del Holocausto. Para estos últimos, la primera generación se encontraría conformada por aquellos que sobreviven, hombres, mujeres y niños, al exterminio. Los hijos nacidos con posterioridad en estas familias se consideran segunda generación.

Los abordajes en el Cono Sur otorgan al concepto de segunda generación mayor amplitud, incluyendo tanto a los niños que eran pequeños durante la Dictadura, como a quienes nacen durante y posterior a ella.

Para el estudio mencionado, CINTRAS (2012: 73) realiza una opción: "Para los fines de la presente investigación hemos utilizado el concepto de segunda generación en su acepción más restringida, similar a la utilizada en los estudios sobre los descendientes de sobrevivientes del Holocausto. Consideramos que con este enfoque será posible percibir con mayor nitidez cómo viaja el trauma en el tiempo y cómo es influido por los nuevos escenarios sociopolíticos".

En la misma línea, en su investigación sobre transmisión transgeneracional, Fischer (2013: 166) observa que distintos miembros de una familia, más allá de su lugar en las generaciones, presentan una marca traumática que tendría más en común cuando se comparte el hecho de haber estado presentes durante el evento en términos cronológicos, quedando en un segundo plano su posición en las líneas de parentesco: "Derivado de este punto, también puede considerarse como una implicancia el hecho de cuestionar lo que 
comúnmente se comprende por generación: ahora ya no es exclusivamente la separación que se hace teniendo en cuenta el nacimiento de la persona como en abuelos, padres, hijos, etc., sino que se considera también el suceso traumático que marcó a la familia, donde en los casos observados, un abuelo y su hijo pertenecerían a la misma generación y los nietos, excluidos cronológicamente del evento, pertenecerían a una segunda generación y no a una tercera desde el punto de vista familiar".

Esta opción es también la que hace más sentido al presente trabajo, por cuanto los hijos de los cuales trata esta investigación se encontraron directamente expuestos a los hechos que comprendemos como traumáticos. Por lo que se les considera primera generación, mientras quienes (en Chile) nacieron ya en gobiernos post-Dictadura configuran una segunda generación.

Se trata de una delimitación operativa que en ningún caso agota las preguntas y formas clínicas posibles de observar y comprender (para intervenir) en los hijos de la dictadura. Tras revisar esta discusión se toma la opción de considerar a este segmento de pacientes como hijos de la dictadura porque nacen en pleno estado de excepción y es en este contexto en el que discurre la formación de sus estructuras psíquicas básicas.

El Primer Informe de la Comisión Nacional sobre Prisión Política y Tortura (Gobierno de Chile, 2004: 508), en un breve apartado sobre consecuencias de la tortura de los padres en los niños, alude a la experiencia de ellos mismos, no sólo a aquella que les es transmitida: "La familia y en especial los hijos se vieron muy afectados al hallarse rodeados por un contexto latente de amenazas y miedo. Los allanamientos, los violentos interrogatorios y la detención de miembros del grupo familiar afectaron emocionalmente a todos. Los niños se sentían muy desamparados al percibir que sus padres tenían miedo, y los padres se sentían desolados al darse cuenta de que no podían proteger a sus hijos. Si el padre estaba detenido, la familia temía por su salud y su vida. Se imaginaban con angustia que estaba sufriendo y temían que pudiera morir, pero rara vez se expresaban esos sentimientos abiertamente. Con todo, los niños absorbían esos temores y esas tristezas, con frecuencia sin entender cabalmente qué estaba sucediendo. A su vez, experimentaban una angustia intensa, que se reflejaba en distintos ámbitos (rendimiento escolar, retraimiento social o conductas fuera de control, entre otras)".

Entonces, el problema que se constituye es el de rescatar la singularidad de una clínica en personas que crecen en un contexto dictatorial, con padres o cuidadores más o menos afectados en lo inmediato, secuelados en el presente y que, marcados por su historia subjetiva particular, incorporan identidades como la de 'víctima' o la de 'hijo de' entre otras. 
Si lo traumático tiene la cualidad de socavar o desmontar estructuras psíquicas que habían sido "logradas" en los afectados directos, de la observación clínica desprendemos que estos eventos tienen la potencialidad traumatógena de interrumpir o dificultar de formas diversas el proceso de instalación de estructuras psíquicas de un sujeto en formación. La consecuencia de ello podría ser una estructura psíquica frágil, con incluso menos recursos que la generación anterior: "muchos estudios proporcionan evidencias de que los síntomas de estrés postraumático son más comunes en los hijos de quienes han vivido experiencias traumáticas, y que la segunda generación posee menos recursos para manejar la enfermedad y las situaciones estresantes que otras personas, pero la transmisión de estos efectos dependerá, en una importante medida, de cómo se gestiona y se afronta el problema" (Salvador, 2014).

Es un hecho clínicamente observado que de los eventos traumáticos existe una transmisión. De ella los hijos dan cuenta, lo que no queda claro en cada paciente es si ha podido hacer de ella un contenido posible de incorporar en una trama de sentido, cuáles elementos contiene de lo traumático, si es que cursa como un contenido encriptado o no inscrito, generando unas identificaciones inconscientes invasivas, radiactivas (Gampel, 2005) producto de una transmisión enrarecida por su irrepresentabilidad.

Siendo así, nuestro desafío continúa siendo la organización de un método de intervención que sea capaz de no obturar lo singular y, al mismo tiempo, reconozca la especificidad de un problema en la particularidad que requiere el enfoque para su tratamiento.

Para el caso de Chile se fue elaborando una concepción sobre la posible reparación de estos efectos y muy especialmente se ha indagado y abierto líneas de investigación en torno a las consecuencias y su trabajo con las generaciones que crecieron en dictadura y las que nacen en la post-Dictadura. Elaboraciones que apuntan a enfatizar la construcción de la propia historia, gravemente accidentada por los hechos de violencia política. Las conclusiones de todas estas décadas de escucha y reflexión son elocuentes: "La segunda generación, los hijos de las víctimas directas, deben convertirse en el puente de los padres con la vida, deben ser el sostén afectivo de los padres, reemplazar la pérdida del ser querido idealizado. Deben anular el daño, hacer desaparecer las vivencias traumáticas, esto permitiría una rehabilitación de la imagen familiar que anularía la marginalidad social". (Díaz, M., 2005; Biederman, N., 1991).

Conforme a lo que se ha planteado, vale decir, las principales distinciones acerca del trauma, lo que se escucha en la clínica cotidiana es la constatación de que los hijos están obligados a hacer algo con la experiencia de los padres; se trata de realidades que impactan en las dinámicas familiares al modo de 
un antes y un después. Como se señaló, la cualidad traumática en su nivel particular para cada caso debe ser investigado. Observamos que existen aspectos comprometidos de una forma que se vincula a lo traumático, mientras otros aspectos subjetivos son desarrollados dentro de parámetros trabajables como síntoma, y otros como potencialidades, tal como en la clínica general. Toda vez que las capacidades de elaboración e inscripción subjetiva de algunas dimensiones singulares en estas experiencias dan muestra de haber sido avasalladas, mutiladas o en casos menos graves se vuelven insuficientes, podemos comprender que son portadoras de un efecto traumático.

Este efecto implica la tendencia a repetir un contenido mortífero: "una vez desaparecida la situación traumática (aquí se refiere al evento), los efectos del trauma continúan como un daño a través del tiempo. Este daño se puede entender como las huellas psicosociales dejadas por la dificultad en el 'procesamiento y elaboración colectiva de los sentimientos de dolor y pérdida, de la angustia resultante generada por el impacto del terrorismo de Estado, el silencio y la impunidad en la sociedad toda'" (SERSOC, 2009:348; en Díaz, 2011:28). Daño respecto del cual comprendemos su origen, mas no su expresión singular.

A ello se suma el paso del tiempo cronológico, que agrega una dificultad en tanto disfraza las situaciones sintomáticas de la actualidad, dificultando los vínculos con lo traumático que, en estos casos, coincide con lo originario: "lo traumático deambula invisibilizado, incubando una intersubjetividad alienada que termina por trasladar a las nuevas generaciones la herencia fantasmática del trauma. En estas nuevas generaciones, por tanto en otro tiempo histórico, lo tanático emergerá representado y simbolizado en otro tipo de fenómenos sociales, probablemente ya no ligados directamente al trauma y a sus orígenes, más bien como síntomas sociales alejados de sus orígenes sociopolíticos: violencia, adicciones, formas de anomia social, suicidios, etc. En cada nueva generación estas relaciones causales del trauma con la realidad contextual originaria se van haciendo más oscuras y mediatizadas, más fácilmente se mimetizan e influencian por los nuevos acontecimientos históricos y por las características personales de los sujetos herederos, que no vivieron directamente los duelos; más fuerte va a ser, entonces, la tendencia al desconocimiento de las conexiones profundas del trauma y más evidente será el riesgo de inclusión estructural de lo traumático a la subjetividad total del país" (Madariaga, 2006: 6). La radicalidad de este planteamiento permite advertir un proceso por el cual van decantando las dinámicas herederas del trauma en la subjetividad personal y de la descendencia en los pacientes, de no existir un trabajo con ellas. Su potencial se vuelve radiactivo, nuevamente tomando las palabras de Gampel (2005).

Hablamos del factor cronológico como hecho de la realidad, aunque con el psicoanálisis conocemos las formas diversas que toma el tiempo en 
lo inconsciente. Conforme a ello, se entenderá que el carácter de "hijo de" responde a un hecho principalmente de realidad psíquica; lo que llamamos realidad externa existe como una cronología de hechos y datos que pertenecen al relato social relativamente consensuado, frente a los cuales nos preguntamos su carácter de evento psíquico. Dado que no nos incumbe el rol de investigadores de la realidad, lo que adquiere relevancia es el estudio de fenómenos subjetivos que develan procesos más allá de la conciencia: los equívocos, producciones oníricas, actos de repetición. Por ejemplo, equívocos respecto de fechas relevantes, como la fecha de detención -señalar, por ejemplo, que su familiar estuvo preso en el Estadio Nacional en 1978 cuando sabemos que este centro de detención no operaba ya en esa fecha- y otros.

La variable cronológica no es, por tanto, demasiado precisa al considerar las descripciones clínicas que considerará este estudio. Existe, sin embargo, un cierto rango etario que, considerado con las precauciones debidas, puede ser pensado en términos generacionales. Podemos situar en este segmento entre los 35 y los 50 años de edad en la actualidad, para fines de una estimación, dado que suelen hallarse regularidades y, por lo tanto, trabajos específicos que a la escucha de estos hijos, hoy adultos, suelen observarse como consecuencias en los proyectos vitales que les convocan, en sus dificultades y síntomas actuales. Situación recurrente es la dificultad de establecer proyectos de vida que impliquen una distancia o diferencia respecto de los padres.

Con distancia se alude no sólo a distancia física, aunque sí es frecuente que estos hijos no hayan dejado el hogar parental. Refiere más bien a la dificultad de concebirse por fuera de cánones familiares heredados: lo ético, lo político. Esta es una característica que podríamos considerar presente en la mayor parte de las familias (no sólo aquellas afectadas por represión política); vale decir, la transmisión implica que se dé aquello. En esta población, sin embargo, según los autores y la observación clínica, se presentan dinámicas notoriamente más rígidas que en las familias que no han sido directamente afectadas por eventos de terrorismo de Estado:

"Según Felsen (1998), las familias de sobrevivientes del Holocausto han sido frecuentemente caracterizadas como familias aglutinadas, debido a características parentales de sobrevaloración y sobreprotección de los niños, y límites poco claros entre los subsistemas conyugal y filial. Este autor señala que la falta de diferenciación de los miembros de una familia podría desalentar la exploración autónoma y la resolución de problemas, inhibiendo el desarrollo de herramientas cognitivas y afectivas en los niños, dificultando de esta manera su desarrollo emocional y su separación de los padres. En Chile, Biedermann (1991), Becker y Díaz (1998) y Díaz (1991, 1995) también describieron que las familias de los perseguidos políticos tendían a transformarse en sistemas aglutinados y más rígidos que las familias no afectadas, 
extremándose las lealtades familiares e interrumpiendo las fases del ciclo de vida" (Faúndez, X., Cornejo, M, 2010: 17).

Nos parece que la cita anterior muestra una realidad clínica cotejable en los pacientes consultantes en la actualidad. Sin embargo, no es generalizable, puesto que muchas veces observamos fenómenos contrarios como el abandono, vínculos altamente desligados, falta de contención básica, incluso casos en donde hubo abandono de las necesidades materiales de los hijos. Lo importante es destacar que en la mayoría de los casos lo aberrante de las marcas que dejaron los eventos traumáticos, alteran y desequilibran vínculos y funciones en las familias. Alteración que cursa también según las posibilidades de estructura psíquica de los involucrados; la experiencia marca en forma indeleble a la vez que no puede sino ser muy singular.

La situación generada por el retorno de un detenido -la mayor parte de las veces habiendo sido víctima de tortura- ha permitido observar que cual sea la forma de alteración de los vínculos, estas dinámicas suelen ser difíciles de modificar y flexibilizarse conforme al paso del tiempo y a las etapas evolutivas: "Las familias de los perseguidos políticos tienden a transformarse en sistemas más rígidos que las familias no afectadas. La rigidificación de las estructuras internas frente a la agresión externa es un fenómeno grupal universal. Todo sistema de lealtades se extrema. Esto apunta a las dos vertientes de todo sistema de lealtades: la cohesión interna y la lucha contra el agresor. Mientras más difícil sea la situación, más difícil es tocar los mitos grupales y más inconcebible es un contacto con el enemigo externo y todo lo que se le parezca" (Biederman, 2014). Nuevamente esto puede cursar de diversas maneras a nivel del relato novelado, y lo que resulta en todo caso muy relevante como consecuencia más allá de los datos contingentes, es que estas rigidizaciones propias de lo traumático dificultan la construcción de una identidad autónoma y, como veremos más adelante, la producción de un lugar psíquico y/o social.

Elena Gómez (2013) analiza un caso clínico -Daniela-, orientado a estudiar a los "hijos de", la generación de actuales jóvenes, entre 20 y 30 años, que contaban con muy corta edad al momento de la situación represiva de sus padres. A partir de su experiencia en ILAS, se constata lo observado también en el contexto de PRAIS, que gran parte de los pacientes no establecen un motivo de consulta asociado a los hechos de violencia política, ni hacen espontáneamente un vínculo con ella. Sin embargo, presentan dificultades principalmente en lo que ella señala como individuación y autonomía: "En la mayoría de los casos se trata de personas que se caracterizan por haber presentado conductas de sobreadaptación y sobremadurez durante la infancia y la pubertad, pero que en determinados momentos de su temprana juventud han experimentado fracasos personales, especialmente en aquellas tareas relacionadas con la individuación y la autonomía. El modo en que esos 
fracasos se expresan es llamativamente intenso, apareciendo notorios estados de desestructuración angustiosa, la mayoría de carácter grave".

Biederman (2014), en su estudio sobre los hijos de los detenidos desaparecidos, sistematiza una serie de perturbaciones que, descritas como consecuencias, muestran la manera en que se alteran procesos de simbolización y vínculos familiares:

\section{"1. La perturbación de un proceso normal de duelo.}

2. La transmisión transgeneracional de patrones conductuales en el seno de las familias.

Este último punto es muy importante porque apunta a la eventualidad de la aparición de perturbaciones en por lo menos la generación que sigue a la que sufrió el impacto directo.

Del estudio de genogramas familiares se sabe que las pautas conductuales tienden a trasmitirse, incluso conductas extremas como el suicidio. El riesgo de suicidio en una familia aumenta en proporción a los suicidios preexistentes en ella. Prevenir un suicidio también es prevenir un mayor riesgo para las generaciones que siguen. La vía de trasmisión de estas pautas transgeneracionales sigue un patrón complejo que no es el caso analizar aquí, pero sí vale mencionar uno de sus elementos principales que es el sistema de lealtades. Cada generación recibe de la que le precede una serie de derechos y obligaciones de la que no se puede sustraer sin pagar un precio. Hasta el derecho a rebelarse en contra del propio sistema de valores está reglamentado en las familias de alguna manera. Hay familias que toleran un amplio margen de divergencias sin entrar en crisis y hay otras que constituyen sistemas muy rígidos, en los que divergencias mínimas ya son fuertemente censuradas. Ya el solo deseo de desarrollar conductas autónomas tiende a generar fuertes sentimientos de culpa en los miembros de estas familias".

Esto no dejaría de tener consecuencias concretas en las condiciones de realidad de los hijos en la actualidad, respecto de su percepción e inserción en la sociedad, vale decir, su relación con el sistema externo al núcleo familiar. En la investigación de Díaz (2011: 101-2) se plantea como conclusión el hallazgo de indicadores de transmisión transgeneracional del trauma; estos determinan una serie de condiciones que se repiten en cuanto a la realidad de la vida de estas personas: "la presencia de la Transgeneracionalidad del Trauma Psicosocial se percibe a través de la permanencia de percepción negativa de la justicia y del reconocimiento social, la dificultad para establecer relaciones de pareja, la escasa participación política, las interacciones radicales, la protección a los padres, la desconfianza y el miedo al abandono. Las principales variables que modulan aumentando la expresión de la 
transgeneracionalidad es el ser mujer, ser hijo/a único o mayor y la ausencia de otro familiar afectado, además de los padres. Es independiente de si uno o ambos padres fueron afectados y del tipo de represión".

A ello se añade la noción de retraumatización, asociada a los avatares del mundo político pasados los años tras el fin de la dictadura. Eventos asociados al mundo de los derechos humanos: hallazgo de osamentas, juicios que se inician en contra de los perpetradores, búsqueda de familiares a través de muestras de ADN, la detención de Pinochet en Londres, la elección de un presidente de derecha, el homenaje a Krassnoff, entre otros. Eventos que para algunos pacientes adquieren una connotación que no podría menos que considerarse retraumatizante: "cada nuevo trauma potencia fuertemente la acumulación de emociones y sentimientos disruptivos, que son compartidos colectivamente (como el dolor, la ira, la desesperanza, etc.), los que no logran ser procesados en esa dimensión de lo social, por lo que adquieren presencia disfrazada en los estilos de relación, en las formas de convivencia cotidiana, en la comunicación, en las formas de organización de la vida social" (Madariaga, C., 2006: 6).

Entonces, advertidos de aquello, evaluamos las expresiones sintomáticas, las actuaciones de los pacientes, sus dificultades en las relaciones más cercanas, sus intentos elaborativos, en suma, su subjetividad, también en relación con las marcas que queda de aquello. Observamos cierta mejoría sintomática de algunos pacientes cuando se insertan en movimientos y reivindicaciones sociales. La marcha, la campaña política, la asamblea, por citar algunos ejemplos, parecen tener un importante efecto terapéutico, que podemos comprender como la producción de un discurso que tiene el potencial de resarcir en algo el debilitado lazo social.

\section{Palabras finales}

Comprendido de esta manera, el trabajo clínico de orientación psicoanalítica apunta a desalienar al sujeto de estas identificaciones rigidizantes, encontrar y relevar lo que de la transmisión constituye un don, entendido en el sentido lacaniano, como una entrega amorosa.

Es posible señalar, a partir del ejercicio clínico y teórico en la temática del trauma político, que lo traumático vivido por las generaciones precedentes, padres o abuelos de un sujeto, no sólo marca la biografía a modo novelesco o de relato ${ }^{5}$, sino que es susceptible de generar dinámicas nuevas (es decir,

Freud, en su artículo "La novela familiar del neurótico" (1908), distingue lo accesorio de lo fundamental en la relación del sujeto a sus padres, señalando que la marca que dejan estos primeros vínculos es indeleble y genera un guion, una novela narrativa y subjetivante. El ex- 
inéditas en las generaciones precedentes) en las funciones parentales (materna y/o paterna), otorgando referentes específicos en el período edípico y adquiriendo un carácter determinante en la configuración de la estructura subjetiva.

\section{Referencias bibliográficas}

\section{a) Artículos}

Aceituno, R. (2006). "Trauma, memoria y transmisión", en Los retornos de Freud. Chile: Editorial Palinodia.

Aceituno, R. (2013) "Tener lugar", en Espacios de Tiempo, Clínica de lo traumático y procesos de simbolización. Chile: Universidad de Chile.

Aguilar, M., Díaz, M., Gómez, E. (2005). "Análisis de los efectos psíquicos asociados al impacto del Informe en la elaboración de lo traumático en procesos terapéuticos individuales", en: www.ilas.cl/articulos/ilas_4/art_7.DOC, revisado el 16 de octubre de 2014.

Azócar, M. L., Casté, M. T., Soza, P. (2003). "El conflicto político: lo innombrable del conflicto psíquico", en Revista Gradiva 4, 2: 142-150. ICHPA. Chile.

Biederman, N. (2014). "Detenidos desaparecidos: consecuencias para la segunda generación", en http://imagenesparamemoriar.com/2014/08/27/detenidosdesaparecidos-consecuencias-para-la-segunda-generacion/, revisado el 7 de mayo de 2015.

CODEPU (2002). "Labradores de la Esperanza", Tomo Il: Estudio sobre la situación social, trauma psíquico e impunidad en la Región del Maule-DIT-T. En: http:// www. derechos.org/nizkor/chile/libros/maule2/index.html. Extraído 25/05/15, revisado el 15 de julio de 2015

Czermack, M (2003). "Memoria y filiación: 30 años después. Conferencia pronunciada en el Instituto Chileno-Francés de Cultura el 6 de noviembre de 2003", en Lo Social y lo Clínico. Cuadernos de Psicoanálisis N³. Chile: Grupo Psicoanalítico Plus.

trañamiento que se produce en las etapas posteriores a la infancia respecto de estos padres no es sino una reedición de las vivencias que, en muchos de los casos, aparecen como una exaltación de los mismos en otras figuras de un padre mejorado o una madre idealizada. Nuestra atención debe centrarse en la madre como función, su idealización y la forma como el sujeto reedita en la actualidad este vínculo en su entorno, lo mismo que con el padre. 
Díaz, M. (2005). «Efectos Traumáticos de la Represión Política en Chile: Una Experiencia Clínica», en: www.ilas.cl/articulos/ilas_4/art_8.DOC, revisado el 18 de octubre de 2014.

Faúndez, X. y Cornejo, M. (2010). "Aproximaciones al estudio de la Transmisión Transgeneracional del Trauma Psicosocial", en Revista de Psicología, Universidad de Chile, Vol. 19, № 2. Chile. Disponible en http://www.cedocmuseodelamemoria.cl/wp-content/uploads/2012/06/Faundez-Cornejo-2010.pdf, revisado el 19 de marzo de 2015.

García, S. (2005). Revista Uruguaya de Psicoanálisis, 100. En: http://www.apuruguay.org/revista_pdf/rup100/100-garcia.pdf, revisado el 15 de mayo de 2015.

Gómez, E. (2012). "Hay heridas que sanan (IV). Mi cuerpo es tu cuerpo: una forma de trauma relacional temprano", en Revista GPU, 2012; 8: 1: 58-62. En: http://revistagpu.cl/2012/GPU_marzo_2012_PDF/PP_Heridas_4.pdf, revisado el 13 de marzo de 2015.

Kurian-Fastlicht, S. (2012). "Transmisión del Trauma Transgeneracional", en: http://www.yadvashem.mx/stephanie-kurian-fastlicht/transmisin-del-traumatransgeneracional.257.html, revisado el 28 de abril de 2015.

Laurent, E (2002). "El Revés del trauma", en: http://virtualia.eol.org.ar/006/ default.asp?notas/elaurent-01.html, revisado el 4 de enero de 2015.

Madariaga C. (2006). Retraumatización: hacia una conceptualización necesaria. En: http://www.cintras.org/textos/reflexion/r32/retraumatizacion.pdf, revisado el 19 de marzo de 2015.

Millán, G. "Pasan carrozas" (extracto), en: http://metiendoruido.com/2012/09/ cuando-las-palabras-son-resistencia-la-poesia-escrita-en-la-dictadura-militarde-pinochet/, revisado el 15 de enero de 2015.

Pommier, F. (2011). "Ana o el arte de desaparecer y el problema de la negación", en Lo extremo en Psicoanálisis. Chile: Universidad de Chile.

Salvador, I. (2014). Referenciado en: http://www.efesalud.com/noticias/seheredan-algunos-traumas/, revisado el 13 de abril de 2015.

Soler, C (1998b). "El trauma". Conferencia pronunciada en el Hospital Alvarez, el 15 de diciembre de 1998. Texto establecido por Cristina Toro. Inédita.

UNR (1998-9). "Una reflexión psicoanalítica sobre el lazo social: desarrollos transmitidos en el Seminario de la Cátedra Estructura Psicológica Social del Sujeto III de la Facultad de Psicología UNR", en: www.vectorsaludmental.com/.../Una\%20 reflexión\%20psicoanalítica\%20s, revisado el 13 de enero de 2015.

Vezzetti, H. (2011). "La figura del trauma histórico en la formación de la memoria pública". Jornadas Internacionales "Historia, memoria y patrimonio. Las 
conmemoraciones y el Bicentenario entre reflexión y experiencias", en: http:// www.unsam.edu.ar/escuelas/politica/centro_historia_politica/2010\%20 nov\%20Ponencia\%20Jorn\%20His\%20Mem\%20Patrim.pdf, revisado el 27 de septiembre de 2014.

Werba, A. (2002). "Transmisión entre generaciones. Los secretos y duelos ancestrales", en Psicoanálisis de la Asociación Psicoanalítica de Buenos Aires, 24, 295-313. En: http://www.apdeba.org/wp-content/uploads/werba.pdf, revisado el 15 de enero de 2015.

\section{b) Libros}

Assoun, P. (2001). El perjuicio y el ideal: hacia una clínica social del trauma. Argentina: Ediciones Nueva Visión.

Aulagnier, P. (1975). La violencia de la interpretación. Del pictograma al enunciado. Buenos Aires: Amorrortu Editores.

Benyakar y Lezika (2005). Lo traumático: clínica y paradoja. El proceso traumático. Volumen 1. Buenos Aires: Editorial Biblos.

Cabrera, P. (2014). Construcciones: clínica de lo traumático y figurabilidad. Chile: Universidad de Chile.

Canedo, L. (2008). La escritura del caso, un ejercicio de lectura. Trabajo presentado en la Sesión inaugural del Seminario del Campo Freudiano de Barcelona, el 18 de octubre de 2008. En: http://www.scb-icf.net/nodus/contingut/article.php?art $=312 \&$ pub=4\&rev=40\&idarea=7, revisado el 15 de julio de 2014 .

CINTRAS (2012). Prevención del daño transgeneracional en segunda generación. Trabajo psicosocial de grupo. Chile: CINTRAS.

Davoine y Gaudelliere (2011). Historia y Trauma, la locura de las guerras. Buenos Aires: Fondo de Cultura Económica.

Deleuze, G. y Guattari, F. (1988). Mil Mesetas: Capitalismo y esquizofrenia. España: Pre-textos.

Díaz, D. (2011). Transgeneracionalidad del Trauma Psicosocial en descendientes de afectados por la represión política en Chile. Seminario de Licenciatura para optar al Grado de Licenciada en psicología. En: http://bibliotecadigital.indh. cl/bitstream/handle/123456789/490/tesis.pdf?sequence=1, revisado el 20 de agosto de 2015.

Dör, J. (1998). El padre y su función en psicoanálisis. Buenos Aires: Ediciones Nueva Visión.

Fischer, J. (2013). Transmisión transgeneracional del trauma politico vivido en Chile en la dictadura militar en descendientes de víctimas: un abordaje psicoanalítico 
en la tercera generación familiar. Memoria para optar al título de psicólogo, Universidad de Chile. http://190.98.219.232/ tesisdh/Tesis_PDF/Tesis\%20Fischer. pdf, revisado el 20 de octubre de 2014

Freud, S. (1915). De guerra y muerte, temas de actualidad. En Obras Completas, Vol. XIV. Buenos Aires: Amorrortu Editores.

Freud, S. (1908). La novela familiar del neurótico. En Obras Completas, Vol. XII. Buenos Aires: Amorrortu Editores.

Freud, S. (1913). La negación. En Obras Completas, Vol. XIX. Buenos Aires: Amorrortu Editores.

Freud, S. (1923). El yo y el ello. En Obras Completas, Vol. XIX. Buenos Aires: Amorrortu Editores.

Freud, S. (1937). Construcciones en el análisis. En Obras completas, Vol. XXIII. Buenos Aires: Amorrortu Editores.

Gampel, Y. (2005). Esos padres que viven a través de mí. Buenos Aires: Paidós.

Garcés, M. y Nicholls, N. (2005). Historia institucional de la Fundación de Ayuda Social de las Iglesias Cristianas FASIC. 1975-1991. Santiago: LOM Ediciones.

González, M. (2004). Trauma, Memoria y Reparación. Cuadernos de Psicoanálisis NN2. Chile: Grupo Psicoanalítico Plus.

Informe de la Comisión Nacional sobre Prisión Política y Tortura (2004). Chile: Comisión Nacional sobre Prisión Política y Tortura.

Insúa, G., Restuccia, M., Caffarini, A., Tanzi, C., Vallone, N., Arche, L., Cons, I. (2008). De un trauma no sexual. Aportes teóricos y clínicos. Buenos Aires: Letra viva.

Lacan, J. (1958). Las formaciones del inconsciente. Clase del 15 de enero. Buenos Aires: Editorial Paidós.

Lacan, J. (1949). El estadio del espejo como formador del yo -je- tal como se nos revela en la experiencia psicoanalítica. En Escritos I. México: Siglo XXI.

Lacan, J. 1972-73. Seminario XX: Aún. Clase 3: "La función de lo Escrito".

Le Gaufey (1993). La evicción del origen. Argentina: Edelp Editorial.

Lira, E., Becker, D. 1989 (comp). Todo es según el dolor con que se mire. Chile: Editorial Instituto Latinoamericano de Salud Mental.

Loveman, B., Lira, E. (2005). Políticas de Reparación: Chile 1994-2004. Santiago: LOM Ediciones.

Mannoni, O. (1973). Ya lo sé, pero aun así, La otra escena. Buenos Aires: Editorial Amorrortu. 
Piper, I. (2005). Obstinaciones de la memoria: la dictadura militar chilena en las tramas del recuerdo. Tesis doctoral. Departamento de Psicología Social. Universidad Autónoma de Barcelona.

Puget, J.; Kaës, R. (1988). Violencia de Estado y Psicoanálisis. Buenos Aires: Lumen.

Rabant, C. (1993). Inventar lo real: la desestimación entre perversión y psicosis. Buenos Aires: Nueva Visión.

Soler, C. (1998a), Alomo, M., Muraro, V., Castro Tolosa, S., Lombardi, G. (2014). Variantes de lo tíquico en la era de los traumatismos. Letra viva. Buenos Aires, Argentina.

Sutil, L. y Lazaro, E. (2007). El dolor incomprendido. El sufrimiento de las Víctimas del terrorismo. Romanyá-Valls-Verdaguer. Barcelona: España.

Tort, M. (2007). El padre y el psicoanálisis. Una Historia política. Chile: Editorial Palinodia.

Weschler, E. (2013). Herencias. La Transmisión en Psicoanálisis. Letra Viva. Buenos Aires, Argentina. 